\title{
Emission of pollution from motor vehicles with respect to selected solutions of roundabout intersections
}

The article concerns the assessment of emmision of selected two-lane roundabout functioning in the city of Rzeszow and its alternate turbo version. In the work was considered four scenarios that represent two different in terms of traffic congestion time of day. The results of the emission of selected components of the exhaust gas (NO $\mathrm{X}_{x}$ and particulates PM10) were obtained on the basis of calculations of emission model VERSIT+ Enviver. While the input data for the calculations were taken from the modeled options of roundabouts in the Vissim program. The results from the Enviver program were compared to calculations from mesoscopic model COPERT 5. The results show that the overall reduction in average speed, as well as increased frequency of braking and sudden acceleration, directly contribute to the growth of harmful emissions. However, with respect to comparision of turbo roundabout in regard of currently running two-lane roundabout can be observed reduction of selected components of exhaust gases emission about approx. 1/3.

Key words: emission, roundabout, traffic, urban transport, microsimulation

\section{Introduction}

As the number of motor vehicles continues to increase, so too does the total emission of toxic exhaust gas components. This leads to a deterioration in air quality and people's health. Notwithstanding the fact that steps have been taken to remedy this problem by establishing relevant standards and executing a number of social campaigns and research projects, emissions from road transport still pose a significant threat. Road transport emissions depend on many factors, including traffic volume, road and car features, weather conditions, drivers' behaviour and the type of intersections. At intersections, vehicles usually slow down or stop, causing disruption in traffic flow. Roundabout intersections are safe and effective, and can also improve traffic flow compared to conventional signalized intersections. However, it is not certain, to what extent different solutions of this kind can reduce emissions of toxic chemicals from car exhaust fumes $[4,6,8]$.

The aim of this study is to determine the volume of pollutants emitted by means of road transport for a selected Rzeszów roundabout which is heavily burdened with traffic. At present, the roundabout has two lanes but a turbo roundabout option was additionally modelled to compare emission outputs. In order to obtain traffic-related results, a microsimulation of traffic flow was carried out in Vissim software using the actual traffic values obtained from the traffic count points existing in the city. In total, 4 scenarios representing two times of the day with different traffic volumes were collated. The traffic results obtained were used to determine the amounts of toxic components: nitrogen oxides $\left(\mathrm{NO}_{\mathrm{x}}\right)$ and particulate matter (PM10) emitted by motor vehicles. A COPERT 5 emission model was adopted to verify the emission results obtained by Enviver software.

\section{Methodology of the study}

The intersection chosen for exhaust emission analysis was a two-lane roundabout at the crossing of Warszawska, Marszałkowska, Rycerska and Lubelska streets in Rzeszów. The roundabout has four main entrances, three of which having two lanes. The entrances on the side of Warszawska,
Lubelska and Marszałkowska streets are marked by high traffic volumes, whereas the traffic at the entrance from Rycerska street is light. The traffic on the two-lane entrance roads during the times of commutes and returns home makes the intersection access roads jam over a distance of about $100 \mathrm{~m}$ from the roundabout entrance. The intersection is shown in Fig. 1.

During the measurements, pedestrian traffic was very light and was therefore passed over in further analysis. All the road traffic measurements were taken on 18 Dec. 2015. The intersection geometry data were taken from a satellite photograph found in Google Maps. The photograph was appropriately scaled so that it could be processed in the Vissim traffic microsimulation software. Traffic volume numbers for individual roundabout entrances were obtained from the database of a vehicle weight pre-selection system. Two times of the day were chosen for the testing of emissions. The first time from 8:00 to 9:00 am represents the morning peak hours, whereas the second time from 8:00 to 9:00 pm is marked by light traffic. Total traffic volumes for all roundabout entrances are charted in Fig. 2.

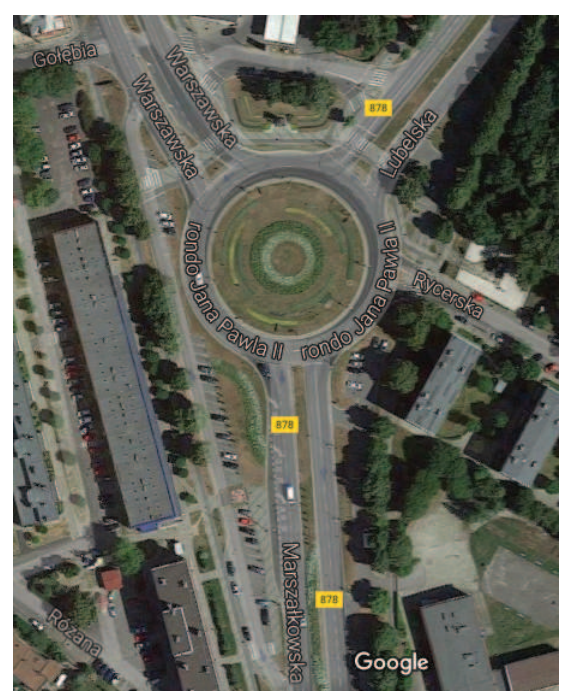

Fig. 1. A view of the selected intersection 


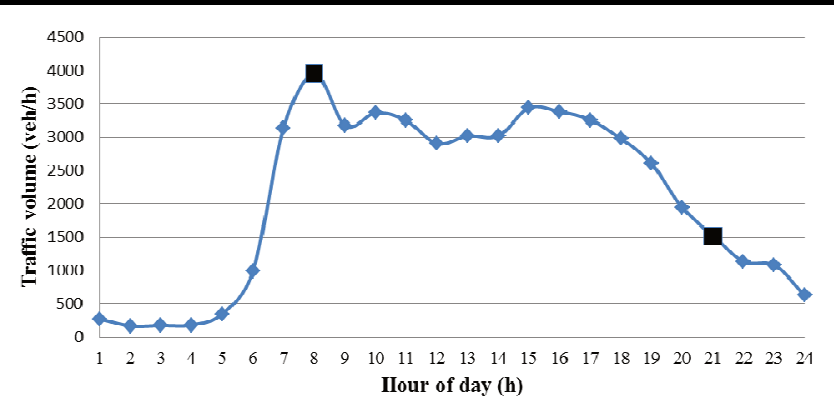

Fig. 2. Aggregate daily traffic volume for selected roundabout at the day of research (black squares means selected part of the day)

\subsection{Modelling traffic and related emissions}

Models of traffic and exhaust gas emission can be divided by their detailed scales as follows: macroscopic (regional), mesoscopic (local) and microscopic (intersections, street stretches). Whereas, models of exhaust gas emission can be differentiated, according to traffic congestion (average speed, vehicle density), to form the following 3 types: A, B and C. A models require input data for particular road situations defined as speed profiles. The data are generated by B models when emissions processes are modelled. Both A and B models are suitable for micro-level analysis. Whereas $\mathrm{C}$ models contain standard driving patterns in their emission model and are suitable for mesoscopic application [11].

PTV Vissim, a microsimulation traffic modelling tool was chosen to estimate emissions at the intersection. Based on the traffic data from Vissim, the emission of toxic exhaust gas components was calculated using TNO Enviver Enterprise. These tools and the models created in them provide reliable data for microscopic emission simulation [1-3, 5]. Additionally, the results obtained were collated with a mesoscopic emission model from COPERT 5 software.

The VERSIT+ emission model, which is used in Enviver software, is a multiple regression model in which the driving cycle of a given vehicle is a variable (A emission model). This model requires that speed profiles are first obtained in Vissim in order to provide a basis for estimation of emission coefficients $(\mathrm{g} / \mathrm{km})$ for different vehicle classes [10]. VERSIT+ contains a series of 246 emission model classes, the algorithms of which are appropriately determined for each vehicle category and each type of toxic exhaust gas component. Using the vehicle data, Enviver can calculate types of emissions like $\mathrm{CO}_{2}, \mathrm{NO}_{\mathrm{x}}$ and PM10. As opposed to the emission factors derived from the New European Driving Cycle (NEDC), the speed profiles used in this model are representative for the actual road conditions [9]. The emission factors $\left(\mathrm{E}_{\mathrm{j}, \mathrm{k}, \mathrm{l}}^{\mathrm{F}}\right)$ are derived from multiple linear regression in order to find empirical relationships between emissions, speed profiles and dynamic variables [12].

Exhaust gas emissions from road transport $[\mathrm{g} / \mathrm{h}]$ for a specific exhaust gas constituent from one or more road sections are calculated using this equation [13]:

$$
\mathrm{TE}_{\mathrm{j}}=\sum_{\mathrm{k}, \mathrm{m}}\left(\mathrm{E}_{\mathrm{j}, \mathrm{k}, \mathrm{l}}^{\mathrm{F}} * \mathrm{TV}_{\mathrm{k}, \mathrm{m}} * \mathrm{~L}_{\mathrm{m}}\right)
$$

where: $E_{j, k, l}^{F}$ - average emission factor $[g / k m], j-$ exhaust gas component, $\mathrm{k}$ - vehicle class, 1 - speed profile, $\mathrm{TV}_{\mathrm{k}, \mathrm{m}}-$ traffic volume [vehicles/h], $\mathrm{m}-\operatorname{road}$ section, $\mathrm{L}_{\mathrm{m}}-\operatorname{road}$ section length $[\mathrm{km}]$.
In the case under study, $\mathrm{NO}_{\mathrm{x}}$ and PM10 emissions were calculated in a spatial resolution of $5 \times 5 \mathrm{~m}$ using Enviver software. The emissions were estimated for urban conditions, that is, the model allowed for a certain proportion of vehicles which were characterized by increased emission of pollutants in exhaust gas due to the phenomenon of engine cold start.

The duration of Vissim traffic simulation was set to 3600 s. Two classes of vehicle were adopted, namely cars (which made up $80 \%$ of all vehicles) and trucks plus buses $(20 \%)$. The car class was made up of $40 \%$ of vehicles with petrol engines, $47 \%$ of vehicles with Diesel engines and $13 \%$ of LPG-powered vehicles. The average vehicle age for cars was set to 8 years. For the truck and bus class, it was assumed that $82 \%$ of the vehicles had Diesel engines and $18 \%$ were CNG-powered buses. The average vehicle age for this class of vehicles was set to 9 years. Emission classes for these vehicles are presented in Fig. 3.
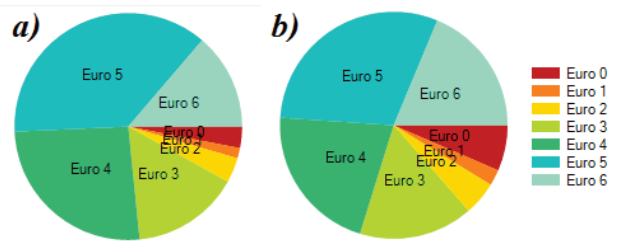

Fig. 3. Emission classes for selected vehicles; a)passenger car's b)trucks and buses

The modelled variants of roundabout intersections are presented in Figures 4 and 5.

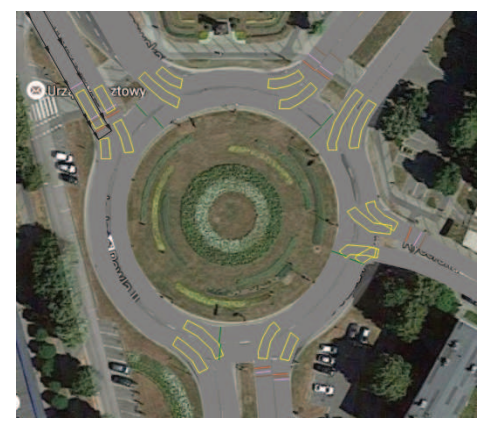

Fig. 4. Vissim model of existing two-lane roundabout

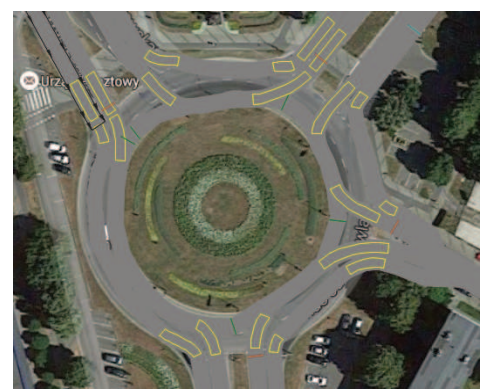

Fig. 5. Vissim alternative model of turbo roundabout

The modelled turbo roundabout introduces a modification for Rycerska street: its entrance and exit become wider to include an additional lane. The main direction of the traffic flow in this roundabout is the stretch from Marszałkowska to Lubelska streets for its highest total traffic volume. 
The traffic volume data for the individual entrances were set in accordance with the actual values collated in Table 1. Whereas parameters related to the right of way were set in the tool in accordance with the data in Table 2.

Table 1. The traffic volume for selected street entries in selected hours of the day, with the division on the analyzed scenarios

\begin{tabular}{|c|c|c|c|c|}
\hline Scenario & Day & Hour & Street entrances & $\begin{array}{l}\text { Traffic intensi- } \\
\text { ty }(\text { veh } / \mathrm{h})\end{array}$ \\
\hline \multirow[b]{4}{*}{$\mathrm{A} 1$} & \multirow{8}{*}{$\begin{array}{l}\text { 18th } \\
\text { December } \\
2015\end{array}$} & \multirow{4}{*}{$\begin{array}{l}\text { 8:00- } \\
\text { 9:00am }\end{array}$} & Warszawska & 1507 \\
\hline & & & Marszałkowska & 1453 \\
\hline & & & Lubelska & 1000 \\
\hline & & & Rycerska & 100 \\
\hline \multirow[b]{4}{*}{$\mathrm{A} 2$} & & \multirow{4}{*}{$\begin{array}{l}\text { 08:00- } \\
\text { 09:00pm }\end{array}$} & Warszawska & 462 \\
\hline & & & Marszałkowska & 761 \\
\hline & & & Lubelska & 296 \\
\hline & & & Rycerska & 47 \\
\hline A3 & \multicolumn{4}{|c|}{ The data as for A1 scenario (optional turbo roundabout) } \\
\hline A4 & \multicolumn{4}{|c|}{ The data as for A2 scenario (optional turbo roundabout) } \\
\hline
\end{tabular}

Scenarios A1 and A2 represent a real road situation that occurred during the measurement of traffic volume in the subject roundabout. Whereas scenarios A3 and A4 are their alternative equivalents to the turbo roundabout option.

Table 2. Priority rules for the simulation

\begin{tabular}{|c|c|c|c|c|}
\hline \multirow[b]{2}{*}{$\begin{array}{l}\text { Roundabout } \\
\text { type }\end{array}$} & \multicolumn{2}{|c|}{$\begin{array}{c}\text { Lubelska/Marszałkowska } \\
\text { streets }\end{array}$} & \multicolumn{2}{|c|}{$\begin{array}{c}\text { Warszawska/Rycerska } \\
\text { streets }\end{array}$} \\
\hline & $\begin{array}{l}\text { Headway } \\
(\mathrm{m})\end{array}$ & $\begin{array}{l}\text { Critical gap } \\
\text { time }(\mathrm{s})\end{array}$ & Headway (m) & $\begin{array}{l}\text { Critical gap } \\
\text { time }(\mathrm{s})\end{array}$ \\
\hline \multirow[b]{2}{*}{$\begin{array}{l}\text { Two-line } \\
\text { roundabout }\end{array}$} & $\begin{array}{l}3.5 \text { (outer } \\
\text { lane) }\end{array}$ & $\begin{array}{l}2.7 \text { (outer } \\
\text { lane) }\end{array}$ & 2 (outer lane) & $\begin{array}{l}2 \text { (outer } \\
\text { lane) }\end{array}$ \\
\hline & $\begin{array}{l}3.8 \text { (inner } \\
\text { lane) }\end{array}$ & $\begin{array}{l}3.2 \text { (inner } \\
\text { lane) }\end{array}$ & $\begin{array}{l}2.6 \text { (inner } \\
\text { lane) }\end{array}$ & $\begin{array}{l}2.9 \text { (outer } \\
\text { lane) }\end{array}$ \\
\hline \multirow[b]{2}{*}{$\begin{array}{l}\text { Turbo round- } \\
\text { about }\end{array}$} & 3.5 & 2.7 & 2 (outer lane) & $\begin{array}{l}2 \text { (outer } \\
\text { lane) }\end{array}$ \\
\hline & - & - & $\begin{array}{l}2.6 \text { (inner } \\
\text { lane) }\end{array}$ & $\begin{array}{l}2.9 \text { (outer } \\
\text { lane) }\end{array}$ \\
\hline
\end{tabular}

It should be stressed that the first 5 minutes of the simulation were excluded from the analysis due to insufficient model saturation. The simulation starts with a null number of vehicles, so, a certain phase of saturation of the road network is needed at the beginning. If this "model warm-up" phase were not allowed for, the true road data would not coincide with the data obtained during the simulation $[5,8]$.

\subsection{Assessment of the model}

The emission outputs from Enviver were collated with the results from the Computer Programme to Calculate Emissions from Road Transport (COPERT 5). COPERT 5 is a model basing its results on the average speed of the vehicles which have passed through a given stretch of the selected route [7]. It is classified as a C-type emissivity model [11]. It is used primarily for calculation of emissivity for a given region or country. It can also be also as a reference model for other microscopic models. In the subject study, the average vehicle speeds obtained from VISSIM formed the input data for the COPERT model. For the scenarios under study, these data are as follows: A1 - 13.1 $\mathrm{km} / \mathrm{h}, \mathrm{A} 2-34.4 \mathrm{~km} / \mathrm{h}, \mathrm{A} 3-20.7 \mathrm{~km} / \mathrm{h}, \mathrm{A} 4-37.8 \mathrm{~km} / \mathrm{h}$.

In summary, Figure 6 shows the overall implementation pattern of the emissivity test procedure for the selected roundabout.

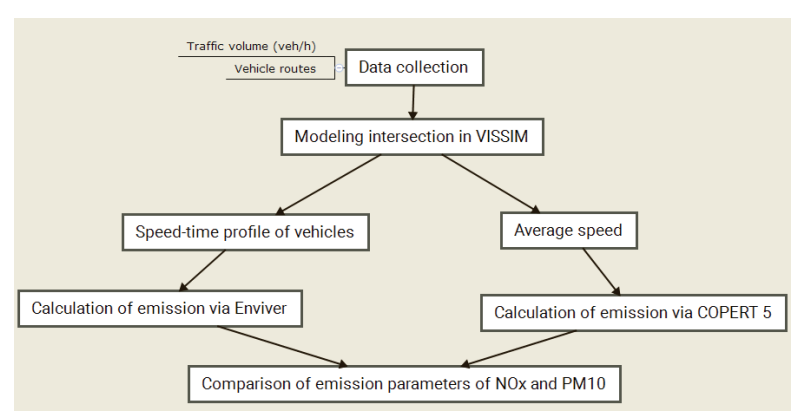

Fig. 6. Diagram of the procedure for selected modelled roundabout scenarios

\section{Results of testing}

The data needed to determine speed-time profiles for each of the vehicles were obtained from VISSIM and had a time resolution of $5 \mathrm{~s}$. These data were essential for ENVIVER to calculate average vehicle speeds for a grid of with a resolution of $5 \times 5 \mathrm{~m}$. This provided data for speed changes that occur when vehicles enter the roundabout (Fig. 7).

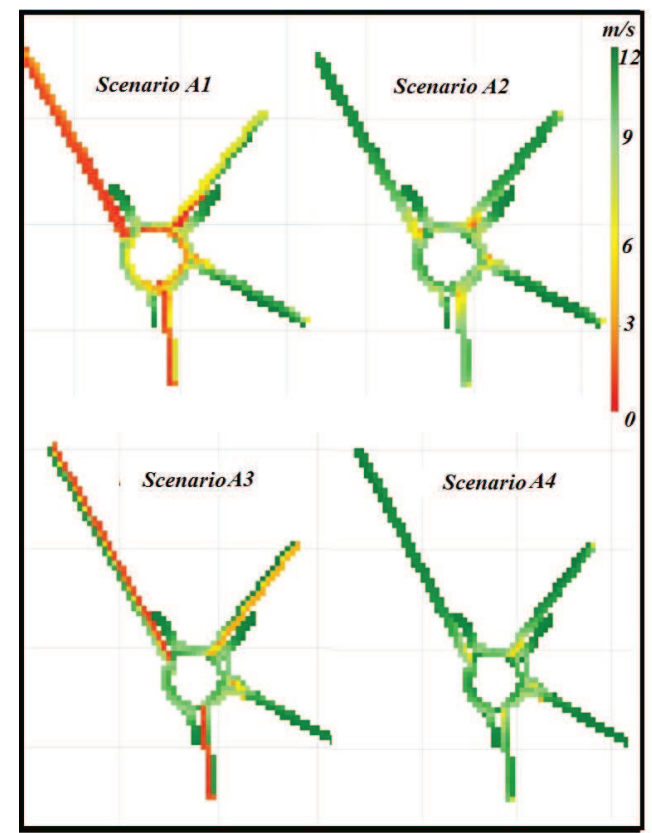

Fig. 7. Resulting average speed of vehicles for considered scenarios

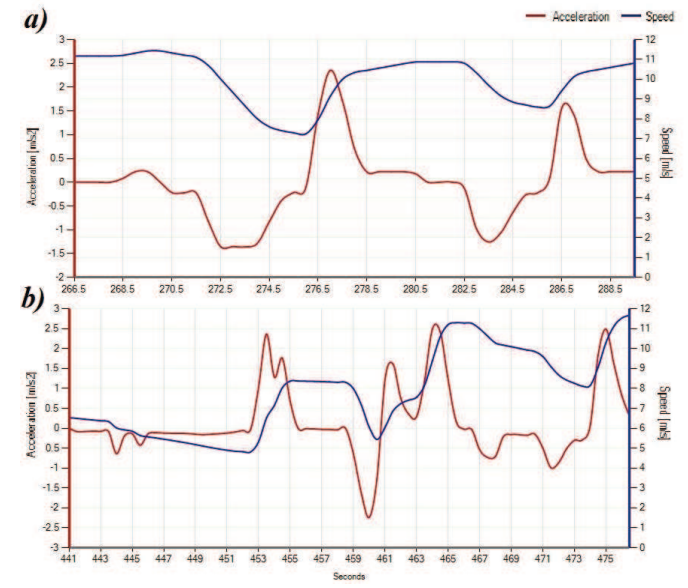

Fig. 8. Speed-acceleration pattern for selected vehicles; a) free flow traffic conditions b)saturated traffic conditions 
For example, Figure 8 presents speed and acceleration profiles for vehicles under different road congestion conditions.

From Figure 8b, or the case of severe traffic congestion, it can be seen that vehicles need more time to pass through the same road stretch compared to the case of a low level of traffic congestion (Fig. 8a). This is due to the fact that the vehicles perform more braking and acceleration operations and this in turn translates directly into an increase in harmful emissions. If the passage times for both the cases are collated, it can be seen that the time lengthens by $35 \%$ for traffic congestion conditions.

\subsection{Results of emission estimation}

The impact of low speeds and, hence, of traffic congestion on car emissions are well reflected in microscopic models.

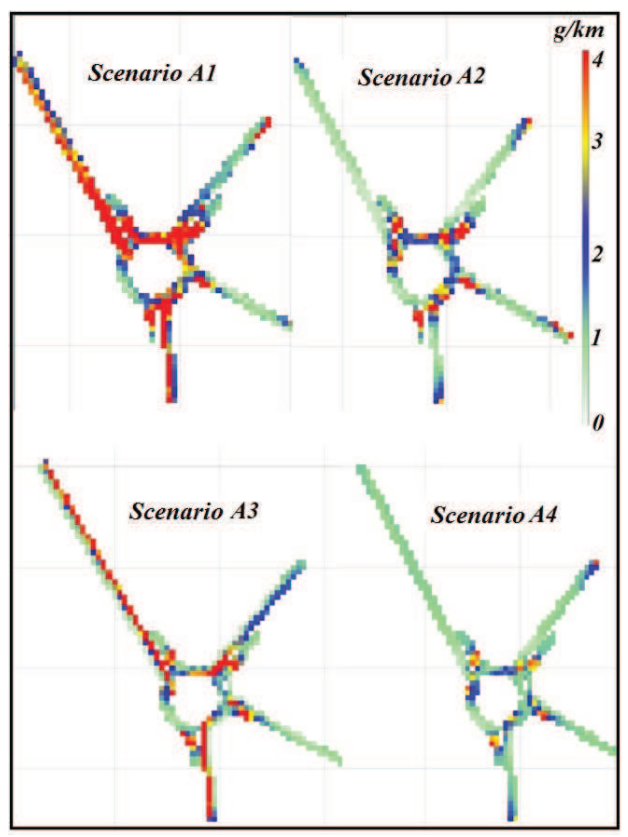

Fig. 9. $\mathrm{NO}_{\mathrm{x}}$ emission results for considered scenarios with spatial resolution of $5 \times 5 \mathrm{~m}$

From Figures 9 and 10 it is easy to notice on which intersection access roads the most massive traffic jams take place and how they influence the emission levels for the selected constituents of vehicle exhaust fumes. In places where the emission is marked red and yellow, vehicles move at low speed, stop for a moment and accelerate one by one, thus contributing to increased emissions. This takes place mainly in the case of congestion as in scenarios A1 and $\mathrm{A} 3$, in access road stretches with the highest traffic volumes. Whereas scenarios A2 and A4, in which the traffic flow is smooth, have definitely lower emission levels than scenarios A1 and A3. This is directly due to a lower number of vehicles and to the constant speed maintained by them while passing through the intersection, without the need to brake or accelerate suddenly.

The results of total emissions and emission factors for $\mathrm{NO}_{\mathrm{x}}$ and PM10 are presented in Fig. 11 and 12. Emissions are lower by approximately $70 \%$ for evening hours compared to the morning peak hours for both the exhaust gas components under study.

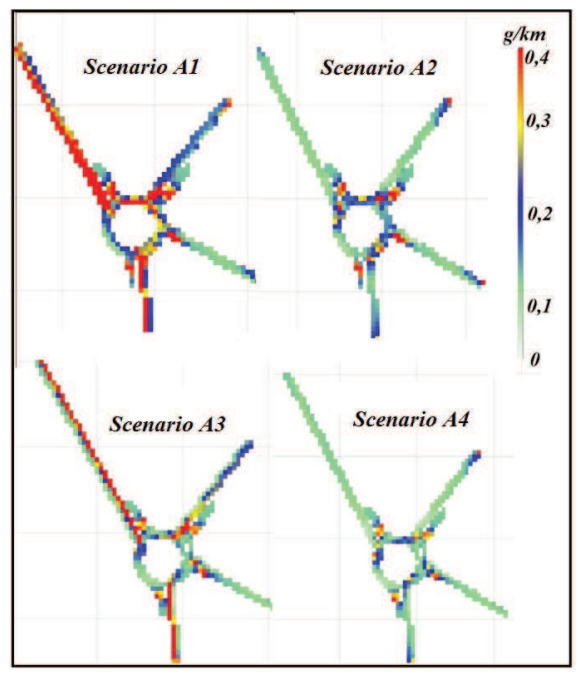

Fig. 10. PM10 emission results for considered scenarios with spatial resolution of $5 \times 5 \mathrm{~m}$

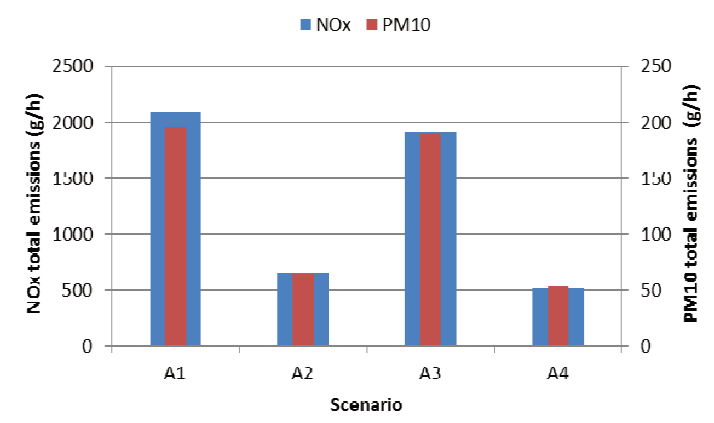

Fig. 11. Total $\mathrm{NO}_{\mathrm{x}}$ and PM10 emissions for considered scenarios

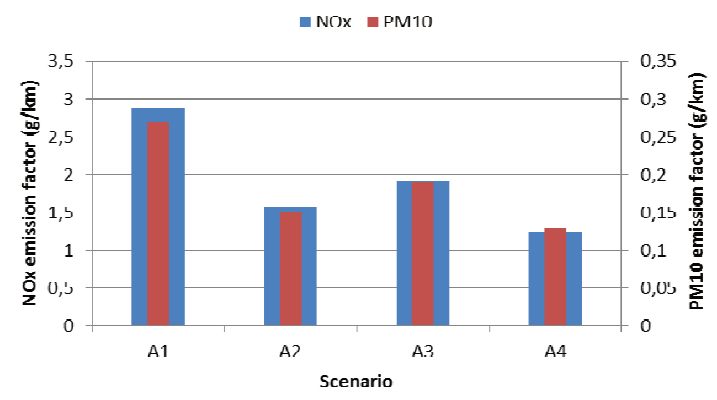

Fig.12. Emission factors for $\mathrm{NO}_{\mathrm{x}}$ and PM10 for considered scenarios

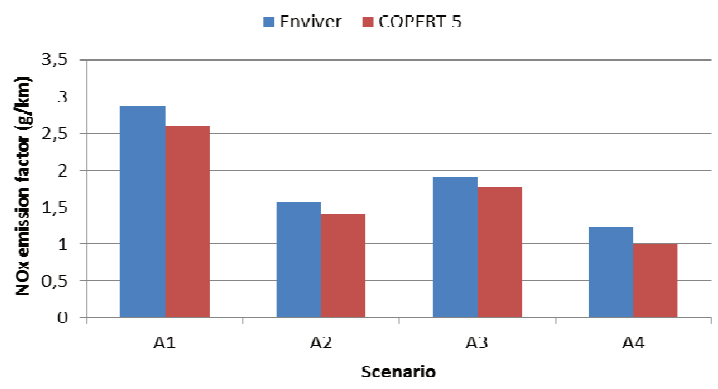

Fig.13. Comparison of Enviver and COPERT 5 emission factors

The results obtained in ENVIVER were compared to the results from COPERT 5 in order to verify them. Figure 13 shows that the $\mathrm{NO}_{\mathrm{x}}$ emission outputs from Enviver and COPERT 5 are near to each other. Differences in the emis- 
sion calculations as performed by the VERSIT + model range from 7 to $18 \%$ compared to COPERT 5. These two models differ mainly in that VERSIT + calculates different emission factors for various road situations which are marked by similar average speeds but different dynamics [12]. VERSIT+ uses driving patterns for specific local situations which it takes from Vissim, while COPERT 5 calculates averaged driving patterns. Therefore, Enviver should reproduce micro-level emissions better [3]. The scenarios with severe congestion and high emission levels involve the greatest deviations from the emission outputs.

\section{Conclusions}

According to the results, the total exhaust gas emission in the area under analysis confirms that the emission significantly changes throughout the day. For the selected exhaust gas components, i.e. $\mathrm{NO}_{\mathrm{x}}$ and PM10, the total emission is 3-4 times higher for heavy traffic hours (scenarios A1, A3) compared to the hours outside the peak hours (scenarios A2, A4). It's certainly connected with the traffic volume and on the consequent of road conditions as well.

\section{Bibliography}

[1] AL ALAMI, Y.R. Application of traffic emission models to the estimation of local pollutant hotspots in South Kensington. 1st Civil and Environmental Engineering Student Conference Energy. 2012, 11. Imperial College London.

[2] BIGAZZI, A., VAN LINT, J.W.C., KLUNDER, G. et al. Traffic data for local emissions monitoring at a signalized intersection. 13th International IEEE Conference "Intelligent Transportation Systems (ITSC)". Madeira Island, Portugal 2010.

[3] CSIKÓS, A., VARGA, I. Real-time modeling and control objective analysis of motorway emissions. Proceedings of Ewgt 2012 - 15th Meeting of the Euro Working Group on Transportation. 2012, 54.

[4] FRANCO, V., KOUSOULIDOU, M., MUNTEAN, M. et al. Road vehicle emission factors development: A review. Atmos. Environ. 2013, 7.

[5] JAWORSKI, A., LEJDA, K., MĄDZIEL, M. Analiza opóźnienia ruchu drogowego dla wybranych rozwiązań odnośnie pierwszeństwa przejazdu na skrzyżowaniu typu X. Monografia pod redakcją naukową Kazimierza Lejdy, Rzeszów 2016.

[6] MAYKUT, N.N., LEWTAS, J., KIM, E., LARSON, T.V. Source apportionment of PM 2.5 at an urban IMPROVE site in Seattle, Washington. Environ. Sci. Technol. 2003, 37.
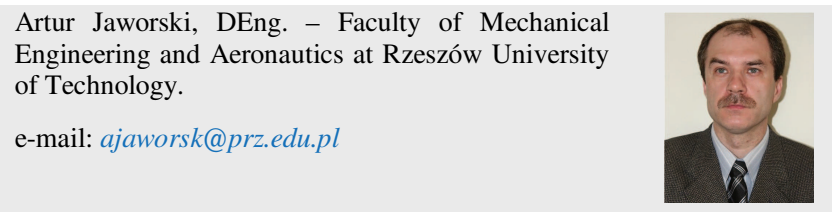

Maksymilian Mądziel, MSc. - Faculty of Mechani-
cal Engineering and Aeronautics at Rzeszów Univer-
sity of Technology.
e-mail: mmadziel@prz.edu.pl
During the morning peak hours, the emission factor for $\mathrm{NO}_{\mathrm{x}}$ increases by $35-45 \%$, and for PM10 - by $32-43 \%$.

With regard to the comparison between the existing twolane roundabout and the alternative option of a modelled turbo roundabout, an increase in average speed by $38 \%$ can be noted under morning congestion conditions. This translates into a decrease in the emission of $\mathrm{NO}_{\mathrm{x}}$ by $31 \%$ and of PM10 by $26 \%$ in favour of the turbo roundabout. For the evening time when the traffic is definitely lighter, one can see an increase in average speed by $8 \%$ for the turbo roundabout and a decrease in the emission of $\mathrm{NO}_{\mathrm{x}}$ by $21 \%$, and of PM10 by $13 \%$ against the two-lane roundabout.

The emission values obtained at the micro-scale were also compared to the mesoscopic model in this study. The collation of the $\mathrm{NO}_{\mathrm{x}}$ emission factor calculations showed differences ranging from 7 to $18 \%$ depending on the scenario. However, these results can be considered satisfactory. Further studies in respect of improvement in the performance of the mesoscopic model should focus on the correction of its calculation algorithms, mainly with regard to emissions other than those from vehicle exhaust systems.
[7] NTZIACHRISTOS, L., GKATZOFLIAS, D., KOURIDIS, C., SAMARAS, Z. COPERT: a European road transport emission inventory model. Inf. Technol. Environ. Eng. 2009.

[8] QUEROL, X., VIANA, M., ALASTUEY, A. et al. Source origin of trace elements in PM from regional background, urban and industrial sites of Spain. Atmos. Environ. 2007, 41.

[9] REXEIS, M., HAUSBERGER, S. Trend of vehicle emission levels until 2020 - prognosis based on current vehicle measurements and future emission legislation. Atmos. Environ. 2009, 43.

[10] SMIT, R., MCBROOM, J. Development of a new highresolution traffic emissions and fuel consumption model. Road Transp. Res. 2009, 18(4).

[11] SMIT, R., POELMAN, M., SCHRIJVER, J. Improved road traffic emission inventories by adding mean speed distributions. Atmos. Environ. 2008, 42(5).

[12] SMIT, R., SMOKERS, R., RABE, E. A new modelling approach for road traffic emissions: VERSIT+. Transp. Res. Part D: Transp. Environ. 2007, 12(6).

[13] SMIT, R., SMOKERS, R., SHOEN, E., HENSEMA, A. A new modelling approach for road traffic emissions: VERSIT+ LD - background and methodology. Report 06.ORPT. 016.1/RS, The Hague. TNO Science and Industry, 2006.

Prof. Kazimierz Lejda, DSc., DEng. - Faculty of Mechanical Engineering and Aeronautics at Rzeszów University of Technology.

e-mail:klejda@prz.edu.pl 